\title{
A COMPLEMENT FIXATION TEST FOR HERPES SIMPLEX INFECTIONS
}

\author{
BY \\ J. A. DUDGEON \\ From the Department of Clinical Pathology, the Hospital for Sick Children, \\ Great Ormond Street, London, and the Walter and Eliza Hall \\ Institute, the Royal Melbourne Hospital*
}

(RECEIVED FOR PUBliCATION APRIL 4, 1950)

The serological diagnosis of virus infections depends for the most part on neutralization and complement fixation tests. Both of these have been described in the case of herpes simplex infections, but the neutralization test is used almost exclusively at present, owing to the conflicting results obtained by complement fixation. The reports in the literature on this subject are at variance with each other. Kraus and Takaki $(1925,1926)$ and Takaki, Bonis, and Koref (1926) reported positive fixation with herpes virus using convalescent human and rabbit sera with a rabbit brain antigen. These workers also reported that they were able to distinguish by this method between herpes and other neurotropic viruses such as vaccinia, rabies, and the virus of Japanese B encephalitis. Their work, however, was not confirmed by Greenbaum and Harkins (1925), Tang and Castaneda (1929), and Gay and Holden (1929). Schultz and his colleagues in a series of investigations (Schultz, 1928 ; Schultz, Bullock, and Lawrence, 1928 ; Schultz and Hoyt, 1928) not only failed to demonstrate complement fixation with herpes but stated that the in vitro combination of antigen and antibody in the case of filterable viruses did not occur, and that the degree of fixation reported by previous workers was due, first to bacterial contamination of the virus antigens, and secondly to a lack of specificity due to inadequate controls. Bedson and Bland (1929) were able to demonstrate specific complement fixation with herpes by using an immune guinea-pig serum and an antigen prepared from guinea-pig pads. This method eliminated the nonspecific and anticomplementary results produced by rabbit brain antigen and rabbit serum. Brain (1932) using the same method as Bedson and Bland was able to show that there was a definite relationship between the presence of complementfixing antibodies and neutralizing antibodies in human sera. Myers and Chapman (1937) found no satisfactory evidence of complement fixation between several different herpes antigens and immune herpes sera, in marked contrast to the results they obtained with vaccinia and virus III. Their iesults were either completely negative, non-specific, or showed fixation only at a low titre. The discrepancy in these findings was probably due to several factors; first, the lack of a sufficiently

* This work, started in London, was completed on a visit to the Eliza Hall Institute, the Royal Melbourne Hospital, in October, 1949. 
potent antigen ; secondly, the use of reagents which tend to give non-specific or anticomplementary results; and thirdly, the lack of sufficiently critical conditions for the test. Casals and Palacios (1941) and Casals (1947) showed that some of the non-specific results with brain antigens could be eliminated by purification of the antigen by some physical method, such as by ultra-centrifugation or by freezing and thawing ; by the use of homologous tissue for the production of immune sera, and by inactivation of sera at various temperatures between $56^{\circ} \mathrm{C}$. and $65^{\circ} \mathrm{C}$., depending upon the species from which they were derived.

The present investigation was carried out to determine whether a more satisfactory antigen could be prepared from the developing chick embryo, as has been the case with other viruses such as influenza, mumps, vaccinia, psittacosis, and more recently with toxoplasma. Preliminary experiments were carried out with antigens prepared from rabbit and mouse brain, guinea-pig pad, and the chorioallantoic membrane. This report deals with the preparation of the chorio-allantoic membrane antigen and its use in the diagnosis of herpes simplex infections. Since this investigation was completed Hayward (1949) has published an account of the preparation and use of an antigen, in many aspects similar to the one described below and which gives similar results in the diagnosis of herpes simplex infections.

\section{Methods and Materials}

In the preliminary stages of this work an attempt was made to find the best source of antigen. Chick embryos of varying ages were inoculated by the following routes: (a) 9-day-old, via the yolk sac, the amniotic fluid being harvested (Nagler, 1946); (b) 11-day-old, via allantoic route; (c) 12-day-old, via chorio-allantoic route ; (d) 13-dayold, via amniotic route. The inoculum was a suspension of a herpes-infected chorioallantoic membrane diluted 1 in 1,000 in $10 \%$ rabbit-serum saline. After 48 hours' incubation at $36^{\circ} \mathrm{C}$. fluids or membranes were harvested and tested for the infectivity titre by the pock-counting method (Burnet and Lush, 1939). It was found that these fluids or membrane suspensions containing virus, as determined by the infectivity titre, also fixed complement when tested with a positive herpes serum (human). There was little difference in the antigen titre between them, the average titre being $1 / 8$ in the case of the amniotic and allantoic fluids, and $1 / 16$ in the case of the chorio-allantoic membrane suspension. Similar results have recently been obtained by Hayward (1949). Occasionally, a few individual amniotic and allantoic fluids were anticomplementary. This was not noticed with the chorio-allantoic membrane suspensions, and as the latter gave such constant fixation at this titre and was easy to prepare, it was used throughout the remainder of the investigation in preference to the other methods.

Strains.-Two strains were used: (a) A local strain, H.S.C./Dew, isolated on the chorio-allantoic membrane from a case of acute aphthous stomatitis in this hospital, and since maintained by passage in the chick embryo ; $(b)$ strain H.F.E., the standard egg-adapted strain used at the Walter and Eliza Hall Institute, the Royal Melbourne Hospital. Both strains behaved in the same way on animal inoculation, although the H.F.E. strain had a higher infectivity titre. Owing to the close antigenic relationship between all herpes simplex strains, no distinction between these two strains is made in this paper.

Diluting Fluid. - Buffered calcium magnesium saline $p \mathbf{H} 7.2$ (Mayer, Osler, Bier, and Heidelberger, 1946) was used as a diluting fluid throughout, in preference to physiological saline.

Antigens.- Twelve-day-old chick embryos were inoculated by the chorio-allantoic 
route with a suspension of herpes-infected chorio-allantoic membrane so diluted in $10 \%$ rabbit serum saline as to give confluent lesions (approximately $1 / 1,000$ in this laboratory). After 48 hours' incubation at $36^{\circ} \mathrm{C}$. embryos were placed in the ice-box for one hour and the membranes were then removed. Those showing confluent lesions were pooled, washed in sterile saline, and ground into a fine emulsion. Sufficient diluting fluid was added to make a $20 \%$ suspension. The suspension was then alternately frozen and thawed six times in a mixture of $\mathrm{CO}_{2}$ and alcohol. This process did not appear to increase the antigen titre but helped to sediment by flocculation extraneous protein material. After centrifugation at 2,500 r.p.m. in an angle centrifuge for one hour the supernatant was removed. This constituted the herpes antigen (herpesC.A.M. antigen*). Membranes from normal embryos (14-day) were harvested and prepared in exactly the same way. This constituted the normal or control antigen (normalC.A.M. antigen). Both antigens were stored at $-20^{\circ}$ C. Merthiolate $(1$ in 10,000$)$ was added as preservative.

Sera and Antisera.-Acute-phase (one to four days) and convalescent-phase (seven to 21 days) sera were collected from all cases of herpes simplex infection under invest:gation, and also from rabbits and guinea-pigs (used for virus isolation) before inoculation and again 21 days later. A hyper-immune guinea-pig $(\mathrm{P} / 12)$ was prepared by a series of injections with a formolized guinea-pig pad suspension, followed by injections with living virus. All sera were stored at $-20^{\circ} \mathrm{C}$. without preservative.

The temperature at which sera were inactivated before use in this test was found to be of considerable importance in eliminating non-specific results. Casals and Palacios (1941) have shown that the non-specific reaction in normal serum could be destroyed by heat without materially affecting the specific antibody titre, the temperature of inactivation depending upon the animal species. In this case it was found that guinea-pig sera and most human sera could be successfully inactivated at $56^{\circ} \mathrm{C}$. for 20 minutes, but nearly all rabbit sera and a few human sera produced non-specific fixation even after inactivation at this temperature. Two positive sera (human and rabbit) diluted 1 in 2 in buffer were inactivated at temperatures ranging from $56^{\circ} \mathrm{C}$. to $66^{\circ} \mathrm{C}$. for 15 minutes. The original serum titre of 1 in 16 in both cases showed no fall in titre at $62^{\circ} \mathrm{C}$.; at $64^{\circ} \mathrm{C}$. the titre fell to 1 in 8 and at $66^{\circ} \mathrm{C}$. to 1 in 4 . Guinea-pig sera tested in the same way showed a slight reduction in titre after inactivation at $60^{\circ} \mathrm{C}$. and were not therefore inactivated beyond this temperature. All other sera were therefore inactivated at $62^{\circ} \mathrm{C}$. for 15 minutes.

Haemolytic System. - Defibrinated sheep cells (formalized) were washed three times in saline, made up to $3 \%$ in the diluting fluid, and mixed with an equal quantity of haemolysin diluted to contain 5 M.H.D. Cells were sensitized for 30 minutes at $37^{\circ} \mathrm{C}$.

Neutralization Tests.-To obtain some correlation between the presence of complement-fixing and the neutralizing antibody, sera were tested by both methods. The neutralization test was carried out by the method suggested by Burnet and Lush (1939). In this test use is made of the fact that the virus of herpes simplex produces visible lesions or pocks after inoculation on to the chorio-allantoic membrane. By inoculating mixtures of serum and virus in constant proportions on to the chorio-allantoic membrane, it can be shown whether a particular serum will inhibit the production of such lesions or not. In practice, individual pock-counts should be reduced by at least $50 \%$ before it can be stated that a particular serum contains neutralizing antibodies. In this investigation the results were quite clear-cut. Sera with neutralizing antibody present produced at least a $90 \%$ reduction in the pock-count in all cases.

* C.A.M. is used as an abbreviation for chorio-allantoic membrane to designate the source of the antigen. 


\section{Complement Fixation Test}

Antigen Titration.-The titres of the herpes-C.A.M. and normal-C.A.M. antigens were determined by the method set out below using titration with both a normal and a positive serum (Table I). Both these sera $(P / 12)$ were tested for the presence of

TABLE I

COMPlement-fiXation Titres of Herpes-C.A.M. and Normal-C.A.M. ANTigens

\begin{tabular}{|c|c|c|c|c|c|c|c|c|c|c|c|c|}
\hline \multirow{3}{*}{ Sera* } & \multicolumn{12}{|c|}{ Antigen Dilutions in $\mathbf{C a}++\mathbf{M g}++$ Saline } \\
\hline & \multicolumn{6}{|c|}{ Herpes-C.A.M. Antigen } & \multicolumn{6}{|c|}{ Normal-C.A.M. Antigen } \\
\hline & $1: 2$ & $1: 4$ & $: 8$ & $: 16$ & $1: 32$ & $\begin{array}{l}\text { Antigen } \\
\text { Control }\end{array}$ & $1: 2$ & $1: 4$ & $1: 8$ & $1: 16$ & $\begin{array}{l}\text { Antigen } \\
\text { Control }\end{array}$ & \begin{tabular}{|c} 
Serum \\
Controls
\end{tabular} \\
\hline \multirow{2}{*}{$\begin{array}{l}\text { P/12 acute } \\
\text { N.A.(-) . } \\
\text { P/12 hyper-im- } \\
\text { mune N.A. (+) }\end{array}$} & $\mathbf{0}$ & & $\mathbf{0}$ & 0 & $\mathbf{0}$ & 0 & $\mathbf{0}$ & $\mathbf{0}$ & $\mathbf{0}$ & $\mathbf{0}$ & $\mathbf{0}$ & $\mathbf{0}$ \\
\hline & 4 & 4 & 4 & 3 & 1 & & 0 & 0 & 0 & 0 & & 0 \\
\hline
\end{tabular}

4 = complete fixation; $3,2,1=$ partial fixation; $0=$ no fixation; $2=$ end-point. N.A. $=$ Neutralizing antibody present $(+)$ or absent $(-)$.

* Both sera were used diluted 1 in 2 and would therefore contain excess antibody if present.

neutralizing antibody, as were all other sera used in this investigation. They were used as control sera throughout these tests but are not included in all the tables.

Preliminary Titration.-Before testing a batch of sera a preliminary titration of the complement was carried out in the presence of the antigen and a negative serum. The antigen was used diluted, as in the test proper, to contain 8 units per unit volume (as titrated above). The serum was used diluted 1 in 2 . After fixation for one hour at $37^{\circ} \mathrm{C}$. the sensitized cells were added. The dilution of complement, which in the presence of antigen and the negative serum showed $50 \%$ haemolysis $(++)$, was taken as the end-point ; this end-point was determined entirely by the appearance of partial fixation based on experience. It was found, after repeated tests, that this short period of fixation gave good results and that the amount of complement necessary for the test could be assessed more accurately by this preliminary titration. The antigens were never found to be anticomplementary by themselves, but there was usually a slight reduction in titre in the tube containing complement, antigen, and serum. The complement was used diluted to 2 M.H.D. throughout the test. Although the complement unit was based on the short fixation period, the actual amount of complement in the test proper after fixation overnight at $4^{\circ} \mathrm{C}$. was likely to be slightly less than 2 units.

Test Proper.-Unit volumes of $0.1 \mathrm{ml}$. were used throughout the test. Sera were inactivated as described above and serial twofold dilutions made from $1: 2$ to $1: 128$. Antigen (8 units) was added to each tube, followed by 2 M.H.D. complement. Each test was set up with the herpes-C.A.M. and normal-C.A.M. antigens and with a positive and negative serum. After overnight fixation at $4^{\circ} \mathrm{C}$. the sensitized cells were added $\left(0.2 \mathrm{ml}\right.$.). The results were read after a further period of incubation at $37^{\circ} \mathrm{C}$. for 30 minutes, the dilution of serum showing $50 \%$ fixation being taken as the end-point.

\section{Results of Complement Fixation}

The results of this test in various types of herpes simplex infection are shown in the following tables.

Virus Identification.-This test was used as a means of rapid identification of 
lesions on the chorio-allantoic membrane. Suspensions of several such membranes were made and tested by the method described above, using a normal and a vacciniainfected membrane as controls. The results of these tests showed specific fixation to a titre of 1 in 16 with the membrane under test and a positive herpes serum, and no fixation with the control membranes.

In addition, the antigen was centrifuged at 15,000 r.p.m. for one hour in a horizontal centrifuge in order to sediment the virus elementary bodies. The supernatant was removed and the deposit resuspended in a volume of saline equivalent to the original uncentrifuged material. The complement-fixation titre of the supernatant showed a twofold drop in titre and over a 1,000-fold drop in the infectivity titre. The resuspended elementary particles fixed complement, though to a lesser extent than the original material, but the infectivity titre was the same. This suggested the presence of a soluble antigen in the supernatant. Since this work was completed Hayward (1949) has clearly shown that the complement-fixing antigen is due to a specific soluble substance which can be separated from the virus particle by high-speed centrifugation.

Complement Fixation Titres of Acute and Convalescent Sera. - The titres of four sera are shown in Table II. The sera $\mathrm{P} / 2$ were obtained from a guinea-pig

TABLE II

Complement-fixation Titres of Acute and Convalescent-phase Sera with HerpesC.A.M. AND NORMAL-C.A.M. ANTIGENS

\begin{tabular}{|c|c|c|c|c|c|c|c|c|c|c|c|c|c|}
\hline \multirow{3}{*}{ Sera } & \multirow{3}{*}{ N.A. } & \multicolumn{12}{|c|}{ Serum Dilutions in $\mathrm{Ca}++\mathbf{M g}++$ Saline } \\
\hline & & \multicolumn{6}{|c|}{ Herpes-C.A.M. Antigen } & \multicolumn{6}{|c|}{ Normal-C.A.M. Antigen } \\
\hline & & $1: 2$ & $1: 4$ & $1: 8$ & $1: 16$ & $1: 32$ & $\begin{array}{l}\text { Antigen } \\
\text { Control }\end{array}$ & $1: 2$ & $1: 4$ & $1: 8$ & $31: 16$ & $\begin{array}{l}\text { Antigen } \\
\text { Control }\end{array}$ & $\begin{array}{l}\text { Serum } \\
\text { Controls }\end{array}$ \\
\hline \multirow[t]{2}{*}{$\begin{array}{l}\mathrm{P} / 2 \text { (Ac) } \\
\mathrm{P} / 2 \text { (Con) } \\
\mathrm{R} / 1 \text { (Ac) } \\
\mathrm{R} / 1 \text { (Con) } \\
\mathrm{P} / 12+ \\
\quad \text { control }\end{array}$} & $\frac{\bar{t}}{+}$ & $\begin{array}{l}0 \\
4 \\
0 \\
4\end{array}$ & $\begin{array}{l}0 \\
4 \\
0 \\
4\end{array}$ & $\begin{array}{l}0 \\
4 \\
0 \\
4\end{array}$ & $\begin{array}{l}\mathbf{0} \\
2 \\
0 \\
3\end{array}$ & $\begin{array}{l}0 \\
0 \\
0 \\
1\end{array}$ & \multirow[t]{2}{*}{0} & $\begin{array}{l}0 \\
0 \\
0 \\
0\end{array}$ & $\begin{array}{l}0 \\
0 \\
0 \\
0\end{array}$ & $\begin{array}{l}\mathbf{0} \\
\mathbf{0} \\
\mathbf{0} \\
\mathbf{0}\end{array}$ & $\begin{array}{l}0 \\
0 \\
0 \\
0\end{array}$ & \multirow[t]{2}{*}{0} & $\begin{array}{l}0 \\
0 \\
0 \\
0\end{array}$ \\
\hline & + & 4 & 4 & 4 & 3 & 1 & & 0 & 0 & 0 & 0 & & 0 \\
\hline
\end{tabular}

N.A. = Neutralizing antibody. See Table I for key to other abbreviations.

inoculated intracutaneously with vesicle fluid from a case of Kaposi's varicelliform eruption. Sera $R / 1$ were obtained from a rabbit inoculated by the corneal route with mouth washings from a case of acute aphthous stomatitis. The acute-phase sera were collected before inoculation.

Complement Fixation in Primary Herpes Infection.-The serum titres in various forms of primary herpes infections are shown in Table III.

These figures demonstrate the characteristic rise in antibody which occurs as a result of the primary infection with herpes. This is in accord with the findings established by the neutralization test. The serum titres in one case of recurrent Kaposi's varicelliform eruption in an adult (Boake and Dudgeon, 1950) are in marked contrast to those found in the infantile type. Antibody was present in the early 
TABLE III

Comparison between the Complement-fixation Titre and Presence of Neutralizing ANTIBODY

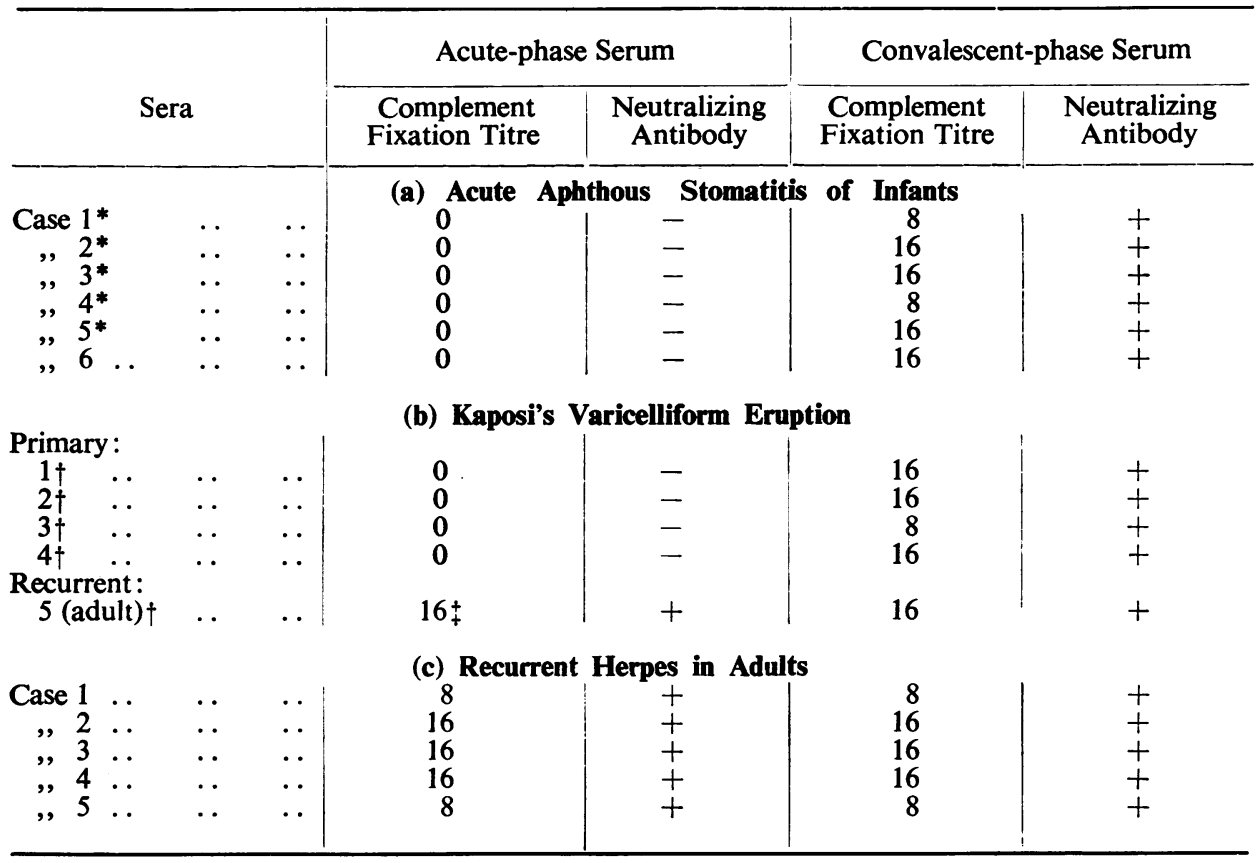

* Virus isolated from mouth washings. † Virus isolated from cutaneous lesions. ‡ Serum taken on fourth day of disease. stages of the infection and no increase in antibody was detected, as was the case with other forms of recurrent herpes infection (Table IIIc).

The antibody titre amongst the normal sera (Table IV) shows a well-distributed scatter amongst the positive sera and complete absence of antibody in the negative sera. Similar findings with normal human sera have been reported recently by

TABLE IV

The Antibody Level in Normal Human Sera

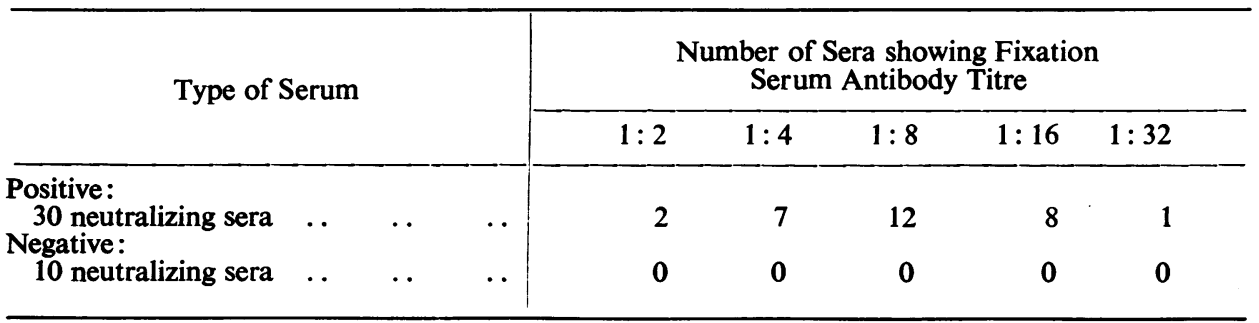

Hayward (1950). This is in accord with the "all or none" phenomenon of herpes antibody (Burnet, 1945), which persists at a fixed level after the primary infection. No fluctuations in antibody titre can be detected by the neutralization test and the 
presence of antibody does not appear to influence, or to be influenced by, recurrent attacks of herpes which are so common. It was amongst this group that several non-specific results were obtained before inactivation of the sera at $62^{\circ} \mathrm{C}$.

\section{Discussion}

A complement-fixation test for the virus of herpes simplex, using an antigen prepared from the chorio-allantoic membrane of the chick-embryo, has been described. With few exceptions, antigens prepared from the chick-embryo have several advantages over antigens prepared from animal and, in particular, brain tissue. They are easy to prepare, they have a high virus content, are bacteriologically sterile, and the risk of non-specific results is reduced. At the same time control antigens from uninfected tissue are easily prepared. In this particular case the chorio-allantoic membrane was used as the source of antigen in preference to the amniotic and allantoic fluids which, although they showed positive fixation, were seldom as constant in titre and on occasions were anticomplementary. The interpretation of any complement-fixation reaction depends to a great extent on the specificity of the reaction. The more sensitive and more specific the test can be made, the greater is its value. This quality of specificity is largely dependent on the antigen itself. Kraus and Takaki (1925) and Takaki, Bonis, and Koref (1926) used an antigen prepared by boiling the supernatant from a rabbit-brain emulsion. Such treatment would almost certainly greatly reduce the antigen titre. Hayward (1949) has shown that the antigen titre is markedly reduced after heating to $56^{\circ} \mathrm{C}$. for 20 minutes. Bedson and Bland (1929) prepared an antigen of high virus content and used a prolonged period of fixation (overnight at $4^{\circ} \mathrm{C}$.) for their tests. The results they obtained were specific. The reaction that may occur between certain tissue antigens and normal sera in some cases fixes complement (Casals and Palacios, 1941). The substance present in the antigen responsible for this reaction can be sedimented at 20,000 r.p.m. (Kidd and Friedewald, 1942) and the antibody-like substance in the serum can be destroyed by heat (Casals and Palacios, 1941 ; Mackie and Finkelstein, 1928). At the same time antisera should be prepared by inoculation of animals with homologous tissue to prevent the formation of antibody to that particular tissue. In one instance in this investigation a rabbit serum was used as a control serum. It fixed complement with both the herpes and normal antigen to a titre of over $1 / 256$. It was later discovered that this animal had three months previously received a course of injections of allantoic fluid containing influenza virus. This was presumably the result of the formation of antibody to the chickembryo tissue. In the present investigation non-specific results were almost entirely eliminated by (1) the use of the chorio-allantoic membrane antigen ; (2) the preparation of hyper-immune sera with homologous tissue ; (3) inactivation of the sera at $62^{\circ} \mathrm{C}$. for 15 minutes. The temperature of inactivation is obviously of considerable importance. The fact that the specific herpes antibody titre in human and rabbit sera was not altered after inactivation at $62^{\circ} \mathrm{C}$. for 15 minutes offers an alternative method of elimination of non-specific fixation. This has been noted in connexion with sera from other virus infections. The antigens were not regularly centrifuged at high speed as the results obtained without this process were satisfactory. On the few occasions that such antigens were centrifuged at 15,000 r.p.m. for one hour they showed only a small drop in antigen titre $(\times 2)$ but a considerable drop in infectivity 
titre $(\times 1,000)$, indicating the presence of a soluble antigen. This confirms the findings recently reported by Hayward (1949). The results of this test in the various forms of herpetic infection are in complete accord with the findings made by the neutralization test. The presence of serum neutralizing antibody as shown in this series was paralleled by the presence of complement-fixing antibody, though the two are not necessarily identical. More work will be needed to determine the relationship between them. In the few cases of recurrent herpes infection investigated there did not appear to be any increase in antibody after the acute phase, and many of the patients had a high titre of antibody, as determined by this method, at the time of infection. The case of recurrent Kaposi's varicelliform eruption was an example of this particular point. In this case the serum was examined on the fourth day (acute-phase) and again on the twenty-first day; no rise in titre was detected. It is possible, of course, that with a more potent antigen changes in antibody titre might be detected, but with this particular method the antibody titre did not appear to change, remaining constant throughout an exacerbation. Several cases of primary herpes infection were investigated and all showed the characteristic rise in antibody which occurs as a result of the infection, in marked contrast to all the recurrent forms of the condition investigated. Complement fixation was also used as a means of virus identification in the laboratory. Lesions on the chorio-allantoic membrane may sometimes be difficult to interpret, as in one instance recently reported by Kipping and Downie (1947). By this method the distinction between variola, vaccinia, and herpes can be made more readily should the occasion arise.

The test appeared to be of value as an alternative diagnostic method in herpes simplex infections, in particular in those instances where a large number of sera have to be examined. It may also be useful in following the course of antibody production in cases of recurrent herpes infections, but so far in the few cases examined no change in antibody has been detected.

\section{Summary}

A complement fixation test for the virus of herpes simplex is described.

The preparation of the antigen and the use of the test in various types of herpes simplex infections are described.

Complement fixation as a means of virus identification is also described.

I wish to express my thanks to the staff of the Walter and Eliza Hall Institute and in particular to Professor F. M. Burnet, F.R.S. (Director), for his advice and assistance during this investigation ; to Dr. Fazekas de St. Groth for frequent and helpful advice ; to Dr. G. Ada for carrying out the high-speed centrifugation and to Dr. A. Isaacs for assistance with one of the cases investigated; to Dr. F. Fulton, of the Department of Bacteriology, the London School of Hygiene, for many helpful suggestions and criticism, and finally to the many physicians, both in this country and in Australia, who so kindly provided material for examination.

\section{REFERENCES}

Bedson, S. P., and Bland, J. O. W. (1929). Brit. J. exp. Path., 10, 393.

Boake, W. E., and Dudgeon, J. A. To be published.

Brain, R. T. (1932). Brit. J. exp. Path., 13, 166.

Burnet, F. M. (1945). Virus as Organism, p. 49. Harvard Univ. Press.

and Lush, D. (1939). Lancet, 1, 629.

Casals, J. (1947). J. Immunol., 56, 337.

— and Palacios, R. (1941). J. exp. Med., 74, 409. 
Gay, F. P., and Holden, M. (1929). J. infect. Dis., 45, 415.

Greenbaum, S. S., and Harkins, M. J. (1925). Arch. Derm. Syph., Chicago, 11, 789.

Hayward, M. E. (1949). Brit. J. exp. Path., 30, 520. (1950). Lancet, 1, 856

Kidd, J. G., and Friedewald, W. F. (1942). J. exp. Med., 76, 543.

Kipping, R. H., and Downie, A. W. (1948). Brit. med. J., 1, 247.

Kraus, R., and Takaki, J. (1925). Med. Klinik., 21, 1872.

- (1926). Klin. Wschr., 39, 624.

Mackie, T. J., and Finkelstein, M. H. (1928). J. Hyg., Camb., 28, 172.

Mayer, M. M., Osler, A. G., Bier, O. G., and Heidelberger, M. (1946). J. exp. Med., 84, 535.

Myers, R. M., and Chapman, M.J. (1937). Amer. J. Hyg., 25, 16.

Nagler, F. P. O. (1946). Aust. J. exp. Biol. med. Sci., 24, 103.

Schultz, E. W. (1928). J. Immunol., 15, 229.

Bullock, L. T., and Lawrence, F. (1928). Ibid., 15, 243. and Hoyt, J. (1928). Ibid., 15, 411 .

Takaki, J., Bonis, A., and Koref, O. (1926). Z. ImmunForsch., 47, 431.

Tang, F. F., and Castaneda, M. R. (1929). J. Immunol., 16, 151. 